\title{
Dr. Grace Barr Kumarakulasinghe (1908-2013)
}

MRCP (E), DCH (Lond), LMS (Cey)

Sri Lanka Journal of Child Health, 2013: 42(3): 175-176

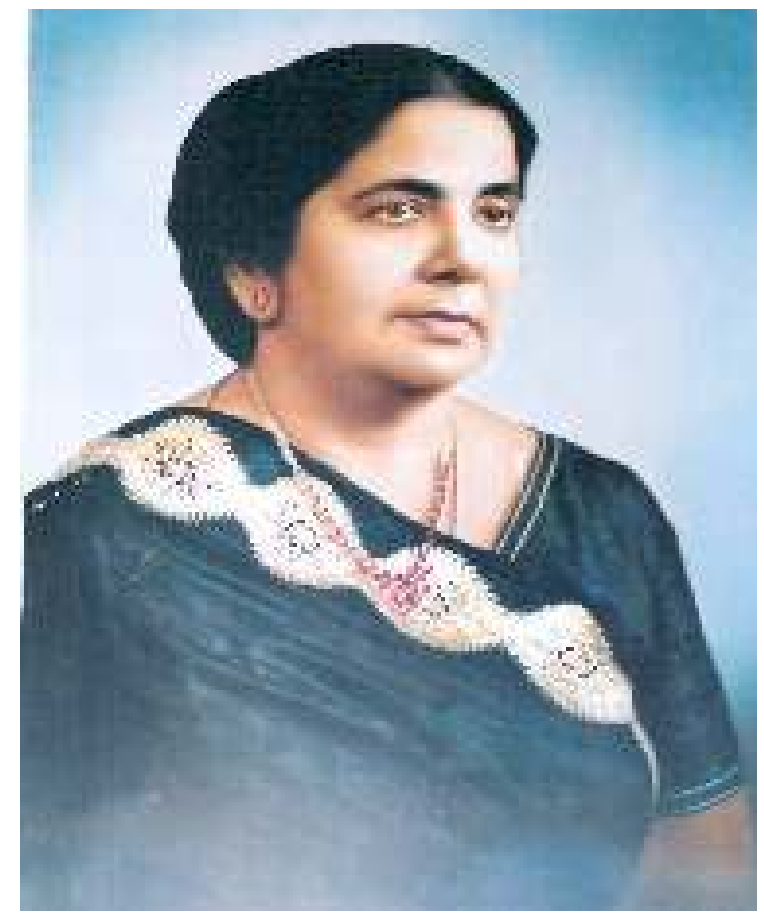

Dr. Grace Barr Kumarakulasinghe was born on $7^{\text {th }}$ August 1908 and died on $26^{\text {th }}$ April 2013. She was 104 years old. Her passing away saw paediatricans of Sri Lanka as well as the entire medical profession in this country lose its oldest living member.

Dr. Grace Barr Kumarakulasinghe, who served the Ministry of Health from 1937 to 1967, made two very significant contributions to paediatrics in Sri Lanka. As one of the first women paediatricians in the country (she and Dr Stella de Silva both returned to Ceylon in the same year, after specializing) she paved the way for women to be employed as equals in the field of medicine. This did not happen without a battle. Although equally qualified, equal status was denied her for a job at the Lady Ridgeway Hospital. Male monopoly was the order of the day. Even the British Medical Journal had only recently stopped calling for applications from "men only". Countless letters written with help from her husband, a prominent lawyer at the time, and a visit to the hospital by the Minister of Health, who happened to be a woman, helped her win the struggle for equality.
Pride, prejudice, prestige and purse were finally won over!

Her second major contribution was her pioneering work with newborns. She was the first paediatrician in the country to be solely entrusted with the care of newborns. This came about in 1954 when posted to the newly created Castle Street Hospital for Women. It was left to her to recognise the special needs of neonates. She founded the "Premature Baby Unit" at this hospital and pioneered record keeping and analysis of neonatal mortality and morbidity in the only two maternity hospitals in the country. Her Presidential Address to the Ceylon Paediatric Association in 1963 was aptly titled "The Newborn".

Her pioneering work was well appreciated by the Obstetricians of the time who invited her to be the Joint Editor of their first ever Journal in Obstetrics and Gynaecology in Sri Lanka. Her co-Editor was Dr. Siva Chinnathamby.

"Dr. Barr Kum" received her early education at Wolfendhal Girl's School and later Ladies College Colombo, where she obtained a first class at the matriculation examination. In an era when science was not taught in girl's schools she set her mind on reading for an Honours degree in English, until older brother Dr. G.S. Sinnathamby (an eminent surgeon) convinced her towards a career in Medicine; a choice she never regretted. It was in her "Pre Med Year" in the University of Ceylon that she first learnt science. On entering the Colombo Medical College she excelled in academia and emerged with First Class honours at the final examination.

Hers was a world paediatricians of today would hardly recognize. I had the good fortune to first meet this gracious lady when she was in her $98^{\text {th }}$ year. Her coherent descriptions of a bygone era sealed a bond of friendship between us and my frequent visits to her home in the quiet environs of Colombo 7 that ensued were enormously enjoyed by us both. Her ring-side observations on the growth of paediatrics in this country made enthralling narratives. 
As a young doctor she had worked at the Lady Havelock \& Lady Ridgeway Hospitals. This was before "The Lady Ridgeway" became a stand-alone institution. Mortality was high, the stench strong and the disease spectrum different. Kwashiorkor, gangrene, polio, heavy roundworm infections and congenital syphilis were rampant. "Four patients to a bed and plenty more on the floor" was how she described the hospital and in the late 1930s her monthly salary was a princely Rs 100 . Her work hours and days were long, and her roster included 48 hours of on call duty. Nevertheless it was with admiration and affection that she remembered her colleagues and teachers.
Dr. Grace Barr Kumarakulasinghe remained the charming, gracious and unassuming person she was, until the very end. She had undertaken arduous work and dangerous encounters willingly and courageously to care for sick children who needed her presence besides them. All this had been for the sheer joy and satisfaction she received. The legacy she left was a community richer through her contribution to neonatology and paediatrics and awoken to the fact that a woman doctor was as good as or better than any man.

May her son Sudhir take comfort in knowing that an angel is watching over him.

Professor Manouri P. Senanayake 